\title{
'Cool' Meanings
}

Tattoo Artists, Body Work and Organizational 'Bodyscape'

Simpson, Ruth; Pullen, Alison

\section{Document Version}

Accepted author manuscript

Published in:

Work, Employment and Society

DOI:

10.1177/0950017017741239

Publication date:

2018

License

Unspecified

Citation for published version (APA):

Simpson, R., \& Pullen, A. (2018). 'Cool' Meanings: Tattoo Artists, Body Work and Organizational 'Bodyscape'. Work, Employment and Society, 32(1), 169-185. https://doi.org/10.1177/0950017017741239

Link to publication in CBS Research Portal

\section{General rights}

Copyright and moral rights for the publications made accessible in the public portal are retained by the authors and/or other copyright owners and it is a condition of accessing publications that users recognise and abide by the legal requirements associated with these rights.

Take down policy

If you believe that this document breaches copyright please contact us (research.lib@cbs.dk) providing details, and we will remove access to the work immediately and investigate your claim. 


\section{'Cool' Meanings: Tattoo Artists, Body Work and Organizational 'Bodyscape' Ruth Simpson and Alison Pullen}

Journal article (Accepted manuscript*)

\section{Please cite this article as:}

Simpson, R., \& Pullen, A. (2018). 'Cool' Meanings: Tattoo Artists, Body Work and Organizational 'Bodyscape'. Work, Employment and Society, 32(1), 169-185. https://doi.org/10.1177/0950017017741239

\section{DOl: https://doi.org/10.1177/0950017017741239}

Copyright (C) The Author(s) २018. Reprinted by permission of SAGE Publications.

* This version of the article has been accepted for publication and undergone full peer review but has not been through the copyediting, typesetting, pagination and proofreading process, which may lead to differences between this version and the publisher's final version AKA Version of Record.

Uploaded to CBS Research Portal: September २०19 


\title{
'Cool' Meanings: Tattoo Artists, Body Work and Organizational 'Bodyscape'
}

\section{Ruth Simpson}

\begin{abstract}
Alison Pullen
Abstract

This article analyses the meanings tattooists as 'body workers' construct around their work. Based on an ethnographic study, the research finds that tattooists adhere to notions of nonconformity, unconventional artistry and professionalism. We locate these meanings within the cultural values and aesthetics of 'cool' as an admired set of attributes and displays which enable tattooists to manage some of the tensions of the work. Combining Bourdieu's concept of habitus with Gagliardi's notion of landscape, we develop the idea of 'bodyscape' to further an integrated understanding of body work as spatialized and embodied i.e. one which incorporates the significance of spatial practices and artefacts, the bodies of those worked upon and the embodied dispositions of workers.
\end{abstract}

Key Words: aesthetic labour, body work, 'cool', tattooing.

\section{Introduction}

Drawing on an ethnographic study of tattoo artists in Sydney, Australia, this article explores the meanings that tattooists give to their work. As a form of body work (Wolkowitz, 2002; 2006) tattooing comprises an aesthetic practice that is performed directly on the body 
and which, unlike other forms of 'beauty work' (hairdressing, nail salons) involves permanent body enhancement and a particularly invasive form of bodily encroachment through the stretching and painful penetration of the skin. At the same time, tattooists engage in body/appearance work or aesthetic labour (Warhurst and Nickson, 2007a) through their own body markings, dress and comportment- branding their bodies to showcase their particular artistic genre. A cultural history of 'unruliness' (Atkinson, 2003) adds a further distinction and specificity to this work, where tattoos have traditionally been seen as an indicator of anti-social behaviour, impulsiveness and lack of self- control (Atkinson 2003; deMello, 2000; Lane, 2014). However, greater regulation and an increase in popularity have helped to challenge some of these negative cultural assessments (one in five people in Australia now have at least one tattoo, McCrindle, 2013). As Patterson and Schroeder (2010) contend, ambiguities nevertheless persist in terms of how the industry is perceived making the meanings given to this unique form of body work a fruitful focus of inquiry.

Following Chugh and Hancock’s (2009) 'integrated' account of aesthetic labour, we focus on the interrelationships between the embodied labour of workers, the 'aesthetic qualities' and embodiment of clients and a range of other factors including organizational artefacts and the situation of work. In so doing, we draw on Bourdieu's $(1977 ; 1984)$ concept of 'habitus' as a set of embodied dispositions and Gagliardi's (1996) notion of organizational 'landscape' whereby artefacts and space potentially combine to produce an organizational 'pathos' namely, a particular set of meanings and ways of perceiving and feeling organizational reality. Drawing on observational field work, informal interviews and conversations with fifteen tattoo artists as well as visual method, we show how tattooists create meanings around non-conformity, unconventional artistry and professionalism. We argue that these form a pathos based on cultural values of a 'cool' aesthetic, conceptualised as a particular, admired set of attitudes, practices and displays (Botz-Bornstein, 2010), 
embodied within the habitus and which help manage tensions associated with the work. Our findings contribute to an integrated understanding of body work as organizational 'bodyscape'. Used in human geography to metaphorically match the body with features of landscape (and vice versa), the concept can encourage thinking of the human form in conjunction with artefacts and space. The paper accordingly develops an understanding of body work which incorporates elements of landscape, materialised in a set of perceptions and meanings, which takes 'worked-upon' bodies into account and the embodied dispositions of body workers - enabling an appreciation of areas of convergence as well as potential tensions that may exist between them.

\section{Body Work and Body Appearance Work}

Tattooing can be positioned within the distinct but overlapping fields of 'body work', defined as work that focuses directly on the bodies of others (Wolkowitz, 2002), and 'body appearance work' (Gimlin, 2007) whereby workers manage their own looks and appearance the latter conceptualised as aesthetic labour (Warhust and Nickson, 2007a; Pettinger, 2010) when appearance and comportment are made to fit with an organizational 'brand'. Both types of body work have particular relevance for work geared towards aesthetic enhancement (e.g. tattooing, hairdressing) where the worker is encouraged to embody the style and nature of the service produced and where relevance might be found in terms of how they interact.

With a focus on the former, Wolkowitz (2002) shows how the body/work nexus - where the body is the immediate site of labour - offers particular meanings and experiences, providing opportunity to examine social relations, corporeality and work-based subjectivity. As Wolkowitz suggests, social relations based on subordination and domination are central to occupations involving work performed on other people's bodies, shaped by demographics (e.g. gender, class) and by definitions of the body in context. For example, the low status of 
care work, often performed by women, may be associated with both gender and the 'dirtiness' of the job through 'intimate, messy contact' (Wolkowitz, 2002: 497) with the bodies worked upon - where awareness of social disadvantage shapes care workers' experiences. At the same time, the frequently supine, naked or physically weakened body in these contexts may give rise to objectification and control by those who administer to them, highlighting the often ambiguous nature of the social relations involved.

More in line with our research context, other literature has explored the meanings attached to and the social dynamics involved in body work geared towards aesthetic enhancement. Black and Sharma (2001) found that workers often expand their roles, for example by generating understandings of a 'deficit' body as lacking in self-love which workers seek to restore. Gimlin (1996) shows how female hairdressers draw on specialist knowledge of beauty culture and see themselves as 'friends and equals' with their clients in order to nullify status differences - a positioning easily undermined by the need to comply with customers' demands. Kang's (2003) work on nail salons highlights the importance of demographic characteristics of the clientele in how the work is carried out, with middle class, white clients being offered a 'higher service' based on physical pampering while others are given a more routinized body labour with minimum emotion work involved. This highlights the potential tensions in the relations between givers and takers of body work (Wolkowitz, 2002) often based on the demographic characteristics as well as the levels of agency involved.

For Chugh and Hancock (2009) these relations do not just rely on the embodied labour of employees and their relative positioning but involve a range of aesthetic processes that find purchase in Gimlin's (2007) identification of 'body/appearance' work'. Defined as the supply of embodied capacities and attributes at the point of entry into employment (Warhurst and Nickson, 2007a), aesthetic labour (as a form of body/appearance work) involves the fashioning of these capacities to fit with a corporate 'ideal'. Workers invest resources into 
creating an acceptable working body (Pettinger, 2010) geared towards producing a particular, distinctive 'style' of service encounter that deliberately appeals to customers' senses (Witz et al, 2003; Warhurst and Nickson, 2007a). Resonant with the 'branded bodies' of tattooists (who often showcase their work through their own body markings), Pettinger (2010) notes ways in which sales assistants, through their appearance, are part of the construction of the store as a branded environment. In this respect, appearance, style and comportment (the 'habitus') have arguably become 'material signifiers' (Hancock and Tyler, 2007) and part of the 'hardware' (Witz et al, 2003) of the organization in terms of the materialisation of the corporate idea and on a par with its physical environment (objects, lay-out, design) that appeal to customers' senses.

This points to a need not only to consider how body work and body/appearance work might intersect in shaping work based meanings, but also to include the potential interplay between 'human and non-human' elements in understandings of how such work is defined and experienced. However, whilst Kang (2003) has highlighted some of the physical dimensions of body work in a nail salon (hot towels, bowls of warm soaking solution, sanitized utensils) that create a pleasurable sensory experience, few studies, as Chugh and Hancock (2009) point out, have made these interconnections a central concern with most research preferring to treat each as a separate dimension. Looking at the aestheticization of hairdressing salons, they show the importance of inter-relationships between the 'embodied agency' and dispositions of workers, the aesthetic qualities and bodies of clients as well as a range of artefacts and 'environmental fabrications' (Chugh and Hancock, 2009: 461) where size, colour and layout of the salons elicit a sense of affluence and vibrancy that is 'brought alive' by appearance and comportment of hairdressers and their clientele.

Responding to their call for more empirical work that pays attention to the embodied and material dimensions of service encounters (such as those found in 'bodywork' and 
'body/appearance' work), Gagliardi’s (1996) notion of 'organizational landscape' and the embodied dispositions captured in Bourdieu's $(1977$; 1984) 'habitus' enable further critique. Organizational landscape refers to the 'material culture' of an organization through architecture, design, artefacts and space. Gagliardi contends that the physical setting and the 'artifacts' within do not comprise a 'naked container' of organizational action but, based in part on prior socially situated meanings and experiences, selectively solicit and cultivate all our senses. These combine to produce a 'world view' or 'pathos' namely, a way of perceiving and feeling organizational reality through appeals to the (visual, aural) senses that, in turn, shape action, beliefs and cultural values with profound implications for the workbased experiences and the communication of meanings.

Bodies (as discussed) are increasingly implicated in these processes as a materialization of an organizational 'pathos' through the dynamics of aesthetic labour. In other words, individual habitus, as a set of embodied dispositions (attitudes, comportment, behaviour, style), shaped by particular social, cultural and historical conditions (Bourdieu, 1977; 1984), interact with space and the artefacts therein to form the organizational 'landscape', generating a pathos or set of meanings. In the context of tattooing, practices of customer service and art come together in tattoo studios - where art is inscribed on the bodies of workers and clients and where space can be seen as lived, embodied and 'made to mean' (Tyler and Cohen, 2010), shaping the service encounter. Following the above, and with this inter-relationship in mind, our research addresses the following questions: What meanings do tattoo artists, as body workers and 'aesthetic labourers' give to their work? How are those meanings constructed? The former captures perceptions and values that help to make up the 'pathos' of an organization or work context while the latter relates to how this world view, through processes of 'landscaping', may be materialised. 


\section{Tattooing and Perceptions of the Industry}

As Botz-Bornstein (2013) argues, despite a rising popularity that has helped to reinforce a contemporary image of tattoos as an artistic form (aesthetic, desirable and 'hip') tattoos are still seen as 'oppositional' with only a gradual shift in levels of acceptability. In this respect, the cultural history of tattooing has had a profound influence over the industry and how it is currently perceived (Atkinson, 2003; Roberts, 2012). Tattooists have traditionally been linked with rebelliousness, associated with an 'underclass' of sailors, the male working class, motorcycle clubs and organized crime (de Mello, 2000; Roberts, 2012). While contemporary tattoos are less a signifier of group belonging - representative instead a strong commitment to the self through individual narratives around spirituality, commemoration and/or personal growth (Botz-Bornstein, 2013) - the influence of these negative attitudes persist (Lane, 2014; de Mello, 2000) and are exacerbated, potentially, in the context of work where there is greater potential for stereotyping and prejudice. Thus, Ellis (2014) found that tattooed individuals were seen by fellow workers as less qualified and less professional than un-modified peers and Timming (2014) highlighted levels of resistance towards employing people with visible tattoos in public services as potentially offensive to customers and clients.

Botz-Borstein (2010) suggests that these more subversive associations can be located within the cultural values and aesthetics of 'cool'. Often researched in the context of marketing and fashion (e.g. Frank, 1997; Patterson and Schroeder, 2010), cool refers to objects including brands and people that are seen as 'non-mainstream' - as both oppositional and subversive, representative of autonomy (Warren and Campbell, 2014) whereby individuals follow their own character or motivations irrespective of the norms, beliefs and expectations of others. To be cool is to remain calm and detached even under stress (Belk et al., 2010) - to be both accepting and subversive as a 'stylised way of offering resistance' 
(Botz-Bornstein, 2010:6). Whilst women can contribute to and draw on styles of cool, it is generally observed as an admired and respected aspect of masculine display (Belk et al., 2010; Botz-Bornstein, 2010). We argue that these cultural values find purchase within the tattoo industry where tattoos and the practices of tattooing may be seen as representative of a desire for authenticity and to 'be oneself' whilst also capturing characteristics such as creativity, rebelliousness and defiance (see below). Taken together, this points to some ambiguity with respect to attitudes towards and perceptions of the industry (Wicks and Grandy, 2007) where tattoos are seen as subversive and, at the same time, as an artistic expression that is more 'mainstream' (Patterson and Schroeder, 2010).

\section{Context and Method}

In addressing these representations, we drew on an ethnographic approach, understood as a 'family of methods' that seeks to understand the social meanings and activities of people in a given setting (Brewer, 2000). Based on our research site (tattoo studios in Sydney), our orientation was towards tattooing as a Western practice rather than as traditional cultural marking (in the case of tā moko which are permanent face and body tattoos for Maori people). To gain access, we visited ten studios where the nature and the purpose of the research were explained to the manager. Seven agreed to take part in the study, allowing us to seek volunteers for interview from their staff.

In each studio, either singly or as a pair, we spent time observing interaction with customers and clients at the entry point, where many of the initial conversations about the type and location of tattoos are carried out. This field work enabled observation of and feel for the tattoo 'space' as well as the practice of tattooing as artists 'worked on' the bodies of clients. Field notes were taken at the time and were later written up in full. Photographs were taken of the studios, tattooists and their artistry which, following Warren (2008), sought to 
capture the atmosphere of the studios as well as the 'aesthetic comportment' of the artists (e.g. in the form of their own body markings). In addition, semi-structured interviews were conducted with fifteen tattoo artists employed within the studios and who volunteered to meet us: three women and twelve men, reflecting the male dominated nature of the occupation (though more female tattooists are entering the industry). All but two were white Caucasian.

Age ranges varied with most in the younger age category, representative of the industry as a whole. One interviewee was in his late 60s and, an apparently well- known figure, had been tattooing for over 30 years. All artists were heavily tattooed to showcase their specialist areas of artistry that might include realism, portrait, Japanese, Asian, traditional, abstract, black and white and/or colour. Nearly all respondents had a background in art or design (having completed a further or higher education programme) and started as an apprentice, an informal studio-based training process and the main means of entry into the industry. From general, more mundane work (including cleaning, making tea, mixing inks, preparing the work stations of existing artists) the aspiring tattooist may eventually be allowed to tattoo the owner or another member of the team. Most had already practised on their own bodies or the bodies of family and close friends. While a few aspired to owning their own studios in the future, none of our interviewees saw themselves moving into an alternative career.

Tattooists are categorised as self-employed in New South Wales, must be taken on by a licensed studio and are required to obtain a Tattoo Artist License, renewable every three years (artists must also undergo a national police check, indicative of the perceptions of criminality still attached to the work). Studio owners must gain an operator's license and failure to adhere to necessary standards of hygiene may mean that a license is revoked. Tattooists provide their own equipment with the studio supplying, gratis, basics such as reclining chairs, paper towels, wraps and cleaning materials. Earnings vary according to the 
skill and popularity of the tattooist with most charging clients by the hour (usually between AD180 to 250). A percentage of their fee is claimed by the studio (normally 50\%). Working hours are flexible and appointments managed either by the artist themselves or in larger and busier parlours by a receptionist.

The timing of the research interviews was crucial with artists consulting their work diaries and fitting us in between clients. Even then, there were frequent interruptions as phones rang or as customers arrived. Interviews took the form of 'conversations with a purpose' (Kvale and Brinkman, 2009) and covered key themes such as personal background and work trajectories; key skills required (e.g. what makes a good tattooists); enjoyable and less enjoyable parts of the job; the nature of interaction with fellow artists; nature of the relationship with clients; perceptions of the industry culture; and future plans. Interviews were transcribed in full and initial observations of the field notes collated. Guided by our research questions as well as by field note observations, interviews were analysed by each author. This was done separately and then collaboratively to identify, discuss and compare themes which then formed the basis for further more detailed analysis. For example, under the theme 'perceptions of work culture', sub themes of autonomy, informality, lack of convention and responsibility were identified (elaborated below).

With one exception, interviews took place within the space of the studio - usually in a seating area provided for clients to wait, to browse through magazines or portfolios and to consult with particular artists. The work of the artists and the bodies of the clients were often in full view in various 'stations': each artist has his/her own space for the reclining chair and personal equipment such as tattoo gun, needles, pigments as well as sterilising and drawing/tracing equipment, leading to quite an untidy, disorderly feel. Improvements in technology have transformed the work of tattooing. For example, the modern electric gun (a hand held machine that drives the pigment into the skin) has reduced the time involved and 
allows greater detail in the work. Depending on the size, design and location, a tattoo can take half an hour for a small flash ${ }^{1}$ icon, while larger more complex patterns can take eight to 20 hours, involving multiple visits

The negative evaluations referred to above have potential to partly define the research encounter. As middle class female academics, our 'knowing practices' and aesthetic experiences and judgements (Warren, 2008) were different from those of the tattooists we interviewed. This could lead, potentially, to a heightening of cultural and symbolic difference between us and the tattooists through, as example, lack of commonality in prior experiences, language and modes of understanding. We therefore sought a 'deep' and sympathetic attentiveness to their accounts whilst being reflexive of our conventional occupational background. To bridge this gap, one of the researchers was tattooed on two occasions as part of the research in order to experience the process of tattooing as well as the spatial and aesthetic environment. This not only broke down barriers but also formed a starting point during interviews for the sharing of thoughts, feelings and experiences.

\section{'Cool' Meanings: Non-Conformity, Unconventional Artistry and}

\section{Professionalism}

Feeling rather intimidated, I entered a crowded waiting area with two shabby sofas and a table containing tattoo magazines and display folders of 'flash' tattoo images. Large pieces of tattoo art were hung on the dark red painted walls: swords, snakes and gothic imagery evocative of the 'grotesque'. Beyond the reception desk in a more brightly-lit area were four beds - all occupied - covered in surgical 'wrap'. The sound of the tattoo guns, working together in a confined space, made a constant, droning noise overlaid by continuous heavy

\footnotetext{
${ }^{1}$ Flash refers to tattoo designs that are often commercially purchased
} 
metal music. There was no conversation. A display case showed skulls, dancing skeletons and body-piercing paraphernalia. Metal trollies - similar to those found on a hospital ward contained towels, creams, sprays and other equipment and there was a pervasive antiseptic smell. On one of the beds lying face down, a big built man in his late 40s has had his leg shaved and a young, white female tattoo artist (heavily tattooed arms, scruffy bleached blonde bob, pierced ears and a nose ring) was focussing intently on her work. Dressed in ripped black jeans, she leant over the large body on the bed. Her striped black and red cotton t-shirt rose up over the belt, exposing her lower back inked, strikingly, with large entangled roses. (Field notes)

Gagliardi (1996) notes that 'sensorially perceptible qualities' of the organizational landscape generate and are illustrative of a pre-existing world view or pathos which can comprise a range of (visual, aural, olfactory) aesthetic signifiers. From the field notes above, these signifiers support a set of meanings based on non-conformity (captured in part in the background clamour of heavy metal music and the female tattooist's bodily aesthetics and displays), unconventional artistry (exemplified through the practices of inking the skin) and professionalism (where commitment to hygiene is evoked through the array of clinical equipment and the presence/smells of anti-sceptic sprays). We connect this pathos, as a schemata of 'perception and taste, models of vision, lenses' (Gagliardi, 1996: 318) to the cultural values and aesthetics of 'cool', embodied in the habitus, and show through our data how the concept of 'bodyscape' - capturing the interaction of space, artefacts, dispositions and practice - enables an integrated understanding of this form of body work.

\section{Tattooing and Non-conformity}


"Like there's a big tattoo culture...it's almost like a bit cliquey you kind of got the cool kids some shops are a bit cooler than others in their minds so they won't hang out with people from other shops" (male tattooist)

Even though all tattooists acknowledged the greater social acceptability of tattoos (and the industry more generally), they also highlighted the continuing associations with an earlier 'unruliness' - foundational, potentially, of a cultural code based in part on rebelliousness and lack of convention and illustrative of a pre-existing, 'non-conformist' pathos or world view. One tattooist illustrated: “As much as you're moving away from that (deviant culture) - it's still got that old punk rock - bikers and rocking out.... and underlying that, a badass (attitude).....” where, within popular slang, a 'badass' refers to someone (usually male) considered tough and impressive with attitudes, behaviours or appearance that denote an independence of spirit and a disregard for authority (www.urbandictionary.com). Portrayals of an earlier, rebellious masculine identity that was seen to have endured within the local industry were often seen as attractive in an oppositional sense through the uptake of a 'risky' lack of conventionality. One tattooists recalled: “(you'd get) a studio full of bikers all looking down on you, rock and roll music playing and full of cigarette smoke and alcohol in the air - it was quite scary...".

While all tattooists were critical of the 'old-style' tattooist (none of whom we seemingly encountered during our research), their legacy could be a source of pride, helping to 'brand' particular studios. From the quote above, some studios are seen as 'cooler' than others, often based on the reputation of particular artists employed. One studio had attracted notoriety through the criminal activities of the owner (jailed for 5 years for a violent altercation with the police) - a situation that led to its ongoing association with anti-establishment values and 
an admired flouting of authority (expressed through getting the 'thumbs up' from a young, male tattooist quoted below):

“We're the most infamous tattoo studio... we've been here for over 20 years and (laugh: description of offence) our shop's been known for a number of years not just as an awesome tattoo shop and friendly staff... and that event, everyone's like giving us the thumbs up, yeah so we're kind of happy we got that tag I guess, it doesn't faze us at all”.

Non-conformity and lack of convention were manifest in a particular 'landscape' of spatial and aesthetic arrangements as well as through a set of discernible bodily comportments. To exemplify, in the image below, a heavily inked tattooist wearing a black singlet adorned with white tattoo imagery and with a gold chain round his neck sits in a relaxed manner in his chair - displaying an easy confidence and lack of formality - and we can see a tumble of tubes of pigment, phones, scissors, cleansing sprays with papers and files stacked overhead. Odd bits of paper and tattoo images adorn the walls and there are wires from a music center in the background. As our field notes indicate, the atmosphere of the studio is often crowded and noisy with loud music and the buzzing of tattoo guns, adding to the semblance of disorder and non-conformity - indicative of the role of artefacts and space in generating a particular pathos or 'world view'.

Figure 1 here

When not working with clients, tattooists are free to do as they wish (they are not paid for this 'in-between' time). Many opt to remain in the studio, sketching and drawing. One male tattooist captured this sense of autonomy: "you just hang out and draw pictures all day" 
where 'hanging out' implies a particular relaxed, informal way of spending time. Another commented:

"I like the atmosphere associated with the tattoo shop - I've always loved the fact that someone can come up here and be themselves, like can swear and say whatever the hell they want. There's no-one judging you...."

This autonomy was reflected through visual imagery, in a highly casual mode of dress: shorts, ragged jeans, dark t-shirts or singlets and with tattoos on full display, highlighting how the group's culture and its shared ethos (the habitus) are partly anchored on the body (Bourdieu, 1984). The photographs below show the body markings of one female and three male tattooists from the study, highlighting varieties in style though they share many of the dark colours and designs evocative of the strange and the sinister (bats, skulls, insects, nocturnal/wild animals, dense patterns that contain eyes or cartoon faces). Unlike small or innocuous tattoos, such body markings are indicative, as Botz-Bornstein (2010) contends, of a 'cool' masculine anti-establishment defiance. These attitudes and displays were also adopted by the three women in the study who all sported large tattoos (as in the second photograph below where Miranda shows a full sleeve and half sleeve tattoo and with body markings also visible on her right leg) highlighting how a 'cool aesthetic' aligns with but is not exclusive to the bodies of men (Belk et al., 2010).

Figure 2

Styles of articulation were equally uninhibited with frequent use of urban slang and swear words - linguistic devices that form part of a shared habitus, highlighting the 'easy autonomy' and casual rebelliousness that are part of the occupation's legacy. Identified by Warren and Campbell (2010) as characteristic of a 'cool aesthetic', this occupational 
'pathos', oriented in part around non-conformity, is embedded within particular spatial practices and displays and enacted through, in Bourdieusian terms, a historically informed set of dispositions based on dress, style, comportment and modes of articulation. This embodied performance highlights not only, as Gagliardi (1996) suggests, the role of the organizational 'landscape' as material culture (artefacts, space) in expressing and communicating an organizational pathos, but how this pathos is embodied in the habitus in the form of practice, style and comportment. We argue that this forms part of a 'bodyscape' that helps to shape the aesthetics and the experience of the work, assisting in the understanding of body work through the interaction of landscape and the human form.

\section{Tattooing as Unconventional Artistry}

"The feeling I got when I done (sic) a tattoo it was amazing, like, f***, I've just changed this person" (male tattooist)

Kosut (2006) contends that the 'mainstreaming' of tattoos is related to their recognition as an art form. All tattoo artists defined themselves as artists, emphasizing the strong artistic element in their work: experimenting with visual ideas; creating and sketching designs; visiting art galleries for inspiration; listening to clients and translating their preferences into an appropriate art form. One commented:

"I know I'm an artist because you can put anything in front of me and I'll make something of it...I'm just drawing pictures on people every day”' (male tattooist)

This 'pattern of sensibility' (Gagliardi, 1996) or pathos is partly known through spatial aesthetics and displays outlined above (wall art, music, the embodied aesthetic and comportment of tattooists themselves) as well as work practices that signify an artistry that transgresses the boundaries of the conventionally creative. Here, unlike more conventional 
artists, tattooists practice their creativity (permanently, painfully) on the skin. This introduces an additional element of skill as well as a dynamic based on the intimate touching and transforming of another's body:

"It's a very intimate experience, especially when working on large pieces that take a lot of time. You've got to stretch the skin to apply the tattoo. It's a very personal endeavor". (male tattooist)

Knowing the texture of the skin and how this is likely to vary from person to person is critical for a successful tattoo. A "good artist" therefore is someone who has both creative ideas and the skills of application:

“It's great to be artistic but, yeah, you've also got to know the body's skin. Everyone has different skin... a good artist has got to change the style according to the person and the skin" (female tattooist)

"Well, a painter knows the canvas, knows the medium knows the paper knows what's happening. But the point is everyone's skin is totally different from each other so I can't look at you and say you've got good skin for a good tattoo. It's only five minutes into the tattoo you realise the quality of the skin". (male tattooist)

Working on a 'living' canvass not only demands extra knowledge and skill but means that the process of tattooing can draw blood ("yeah, sometimes they bleed a lot, you have to slow down and let the bleeding subside") and inflicts pain ("oh yeah, they scream yeah"). Keeping clients relaxed and still are key priorities where the skills and confidence of the tattooist (a steady hand) have implications not only for the clarity and accuracy of the lines drawn, but also for recovery. A sudden movement can cause the tattoo gun to jump and the line potentially to go awry. Additionally, if the needles go too deep, the skin can scar and take 
months to heal. The tattoo 'gun' and pain involved are further reminders of a particular creative practice that is not shared by the rest of the art world.

In this respect, the tattoo gun is not only as an instrument of artistic expression, but also a material reminder of the permanent alteration of the body and, in Modesti's (2008) terms, is emblematic of potential domination and control. The 'body as object' can form the basis of a power dynamic through a form of territorialization (Wolkowitz, 2002). Here, the passive, inert and often supine body is 'laid out' as canvas, worked upon painfully through the interaction with the gun in the creation of an artistic product. Further, the permanence of the marking on the skin comprises a unique signature and authorship of the body that indicates a form of ownership as well as an intimate connection, often the basis for satisfaction and pride:

"Basically, I like leaving my mark...like when I die that's (the tattoo) still going to be there. Like whether they're still alive or dead it's always going to be there. It'll never leave" (male tattooist)

“And doing it on skin, it's kind of like kind of connection with people in a way. You feel a lot more satisfied doing something like that...." (male tattooist)

The recognition of tattooing as an art form not only enables a perception of the work as creative and artistic, key elements according to Gill (2002) that define 'cool' in the context of work, but also helps to confers professional status on those in the industry (see below). Despite this, tattooing is valued as a form of 'unconventional' artistry that transgresses boundaries of what is 'normatively' creative, seen through the medium of the skin and its permanent and painful marking as well as the intimacy of touch. Further, the relations and practices around the tattoo gun that capture the interactive nature 'between things and the development of the self' (Gagliardi, 1996: 313) may be foundational for social relations 
based, in part, on a habitus oriented around 'authorship' (active, creative, in control). Together, this is illustrative of a pathos- a way of perceiving and feeling reality - that not only has a 'scenographic' element as a form of visual communication but which is also rooted in practices that are expressive of an unconventional art form.

\section{Responsibility and Professionalism}

"You don't even think about it (practices around hygiene), you just do it". (male tattooist)

For Bourdieu (1984) the habitus gives rise to possible 'position taking' within a particular context or 'field', with some positional forms seen as more desirable than others. Here, whilst tattooists expressed attachment to an 'unruly' past, thereby reinforcing an 'alternative' cultural expression, they at the same time positioned themselves against the traditional image to draw on meanings around professional integrity and a sense of responsibility towards their clientele. As Belk et al. (2010) argue, a sense of responsibility can be part of a 'cool' performance, based on unselfish actions and concern for others, whilst self-centeredness and conceit ("cocky old dude" in the quote below) can be seen to transgress the detached, responsible self-assurance on which coolness supposedly depends. In this respect, all tattooists referred disparagingly to the 'old school' tattooist as an outmoded legacy, with a seemingly narrow artistic repertoire (“just one idea and that's it!”) and a superior indifference to their clientele ("they just look down on them and talk a lot of shit"), seen as out of place in the modern studio with its diverse clientele. One female tattooist explained, drawing colourfully on conventional discourses of customer care:

"So many people are getting tattooed now, like a lot of older women are getting tattooed and they don't want to just sit around with some cocky old dude who doesn't 
give a shit about what he is doing and just wants to stick some shit on you....so you have to have customer relations."

Meanings around professionalism were supported by particular artefacts (sterile disposable needles, anti-septic wraps), spatial arrangements and embodied practices involving critical techniques to ensure high standards of care, seen as part of the job's routines. The gun is cleaned with sterile solutions after each session and wrapped in plastic to ensure protection from the air. All tattooists wear surgical gloves and prepare the skin in ways that mimic a surgical operation (cleansing with sterile solutions; frequent application of anti-biotic creams). A sheet explaining after-care is given to the client and the tattoo is carefully covered to prevent exposure to germs. The 'urbanesque' wall art, 'streetwear' of the artists and loud music accordingly juxtapose with a pervasive smell of anti-sceptic spray and visible evidence of attention to cleanliness.

The professional, responsible tattooist also listens to the client and gives appropriate advice on the basis of his or her technical and artistic expertise. This sense of professionalism helped to establish a favourable positioning within a social order where the clientele was regarded as uninformed and naïve ("they think they know what they want when they don't") and over whom tattooists often sought to exercise influence in terms of the location and style of tattoo. However, although some forms of tattoo were considered 'out of bounds' particularly in terms of the requested location on the body (e.g. face, neck, genitals) and whilst tattooists were quick to spot impulsive or imprudent requests from 'walk-in' clients who had come straight from the street, customer service pressures (and the need to earn a living) meant that tattooists could feel compelled, as Gimlin (1996) found in the context of hairdressing, to comply with customer wishes. A sense of professionalism, part of the occupational 'pathos' and a source of differentiation and meaningful 'position taking' (Bourdieu, 1984), could therefore be undermined by the need to fulfil (within certain bounds) customer requests, 
especially when these requests were counter to the professional judgements of tattooists concerned. This shows potential for strain between 'landscape', dispositions and practice integrated as 'bodyscape' - and how tension can occur, in this particular case, between a pathos based in part on a sense of professionalism and elements of occupational practice.

\section{Discussion and Conclusion}

In this article, we have combined Gagliardi's (1996) concept of 'landscaping' that captures the significance of artefacts and space in the generation of meanings with bodily aesthetics and practices, through the concept of 'habitus' (Bourdieu, 1977; 1984), to investigate the meanings that tattoo artists as a particular group of body workers give to their work. We highlight a 'world view' or pathos founded upon non-conformity, unconventional artistry and professionalism. Counter attitudes draw on tattooing's aberrant past and a valued and embodied informality as tattooists feel able, within the workplace, to defy certain conventions and 'do their own thing'. Satisfaction is drawn from an art form that is practised unconventionally (permanently, painfully) on the skin while meaning is found through a sense of responsibility and professionalism towards clientele. This pathos is mobilised and transmitted through a particular 'landscape' of artefacts and spatial arrangements as well as practices and bodily displays. Thus, semblances of non-conformity are communicated in part through tattooists' own body art, through wall coverings, skulls, body-piercing paraphernalia that call up traditional, occupational values attached to the 'grotesque' and through a 'musical aesthetic' that indicates resistance to orthodox, work-based disciplinary constraints. Similarly, adherence to regulatory controls is signified through material reminders of and practices around medicalism that involve for example, surgical gloves, anti-biotic creams and anti-septic sprays. 
We locate this world view within the cultural context of 'cool' as part of a work-based 'habitus' which we suggest enables tattooists to manage some of the tensions associated with the work. Identified as an admired 'moral aesthetic' of attitudes, comportment, behaviour and style, 'cool' captures, as our data suggests, artistic creativity (Gill, 2002) as well as an easy and relaxed attitude (Frank, 1977) signifying autonomy (Warren and Campbell, 2014), defiance and an unwillingness to follow mainstream trends (MacAdams, 2001). However, as Warren and Campbell (2014) propose, although 'being your own person' is central to perceptions of 'coolness', autonomous behaviour must be seen as appropriate and legitimate. The traditionally relaxed informality of the tattoo studio is accordingly accompanied by a serious commitment to modern regulatory practices around hygiene and by a strong sense of responsibility to the clientele, with disapprobation expressed towards the 'old school' tattooists who are seen to violate, irresponsibly, these standards of care. This indicates how as an admired cultural attribute the boundaries of cool may shift (MacAdams, 2001; Belk et al., 2010) and how, in this context, its constructions and manifestations can incorporate both non-conformity and the 'mainstream' - the latter deployed through artistic integrity and a strong sense of responsibility to others (Belk et al., 2010). This goes some way to manage tensions between attachments to counter-cultural values, associated with the occupation's 'unruly' past, and contemporary demands of both customer care and regulatory control. Further, the admired aesthetic and 'cultural authority' of cool (Botz-Bornstein, 2010) as a source of differentiation and belonging (MacAdams, 2001) help tattooists contest assaults on their status and authority as both artists and professionals. This materialized through our data in the need to comply with customer's demands, particularly in contexts where those demands overrode recommendations and judgement of the tattooist concerned. A 'cool' detachment ("I tell them (customers) what I think but nothing I can do (sic) if they don't 
listen") and adherence to notions of responsibility, as part of a work-based habitus, may go some way to manage the tensions involved.

We draw here on the notion of bodyscape to develop an integrated account of body work. Often used in human geography, the metaphor captures an interacting system where the 'body is seen as landscape and landscape is regarded as the body' (Porteous, 1986:2) where landscape may be seen to conform to Gagliardi's (1996) articulation of artefacts and space which, as we have shown, are both historically and culturally inscribed. Bodyscape therefore alerts us to the entanglement of landscape, embodied dispositions of the habitus, pathos and practice in other words to the integration of body work, 'body appearance' work, objects and spatial displays as well as to some of the contextually based power dynamics and tensions involved.

This entanglement is exemplified in the social relations implicit in the 'territorialisation' (Wolkowitz, 2002) of the body in this context (supine, inert, to be permanently inscribed) and how these relations are supported and undermined. In terms of the former, aspects of bodyscape combine to create hierarchical relations that, despite pressures to comply with customer's wishes, can serve to position the customer subordinately. As our field notes indicate, entering a studio space with its loud music and 'aesthetics of unruliness' can be an intimidating experience (as one tattooist admitted, "they come in quite shy"). Here, as referred to above, tattooists through their 'cool' attitudes and comportment ('streetwear', inked skin) may embody an authority and admired cultural identity which can shape a service encounter asymmetry where the customer is 'intimidated' (e.g. by the language or the looks of the provider) and rendered subordinate (Warhust and Nickson, 2007b). The 'authoring' of the body through the application of the tattoo gun, as symbol of control, adds a further dimension to this power dynamic based partly on a 'cool' disengagement (Belk et al., 2010) founded on insider knowledge of the tattoo process and an 'unflappable superiority' e.g. in the face of 
another's pain (“you're getting this done so why complain about it?"). 'Bodyscape' can accordingly alert us to the ways in which this shared habitus and the practices around and definition afforded to the bodies of clients combine with artefacts and space to shape particular, hierarchical social relations in context - entanglements that are arguably brought closer together in the occupation of tattooing because of the nature of work performed on the skin.

Although Wolkowitz (2002) and others in the area of body work have pointed to the significance of identity characteristics such as gender and class for how such work is experienced (and while we do not deny the significance of these factors), we have foregrounded the importance of the history, culture and aesthetics of an occupational 'landscape' for a shared, work-based habitus that helps generate particular meanings. In so doing, we have highlighted evident power relations, identity formations and tensions involved and how these are reflected in (and negotiated through) a pathos or world view that is historically and socially inscribed, grounded in artefacts and space. In developing a spatialized and 'fully embodied' understanding of body work as 'bodyscape', this article has emphasized the significance of situated aesthetics, objects and practices which not only takes the 'worked-upon' bodies into account but also incorporates the embodied dispositions of body workers - and how they interrelate to manage meanings and some of the tensions associated with the work.

\section{References}

Atkinson, M (2003) Tattooing and Civilising Processes: Body Modification as Self-Control, The Canadian Review of Sociology and Anthropology, 41 (2): 125-146.

Belk, R Tian, K and Paavola, H (2010) Consuming Cool: Behind the Unemotional Mask, Research in Consumer Behaviour, 12 (1): 183-208. 
Black, P. and Sharma, U. (2001) Men are Real, Women are "Made Up": Beauty Therapy and the Construction of Femininity, The Sociological Review 49: 100-16

Botz-Bornstein, T (2010) What does it Mean to be Cool? Philosophy Now, Oct/Nov, 80: 6-7. Botz-Bornstein, T (2013) From Stigmatized Tattoo to the Graffitied Body: Femininity in the Tattoo Renaissance, Gender Place and Culture, 20 (2): 236-252.

Bourdieu, P. (1977) Outline of a Theory of Practice, Cambridge MA: Cambridge University Press

Bourdieu, P. (1984) Distinction: A Social Critique of the Judgment of Taste, Cambridge MA: Cambridge University Press

Brewer, J (2000) Ethnography. Open University Press, Buckingham.

Chugh, S. and Hancock, P. (2009) Networks of Aestheticization: The Architecture, Artefacts and Embodiment of Hairdressing Salons, Work Employment and Society, 23 (3): 460-476

De Mello, M (2000) A Cultural History of the Modern Tattoo Community, Durham NC, Duke University Press,

Ellis, AD (2015) A Picture is Worth One Thousand Words: Body Art in the Workplace. Employee Responsibilities and Rights Journal, 27(2): 101-113.

Frank, T (1997) The Conquest of Cool: Business Culture, Counter-Culture and the Rise of Hip Consumerism, Chicago: University of Chicago Press.

Gagliardi, P (1996) Exploring the Aesthetic Side of Organizational Life in Clegg, S and Hardy, C (Eds) Studying Organizations, London: Sage, 311-326

Gill, R (2002) Cool, Creative and Egalitarian? Exploring Gender in Project-based New Media Work in Europe, Information, Communication and Society, 5 (1): 70-89. 
Gimlin, D. (1996) Pamela's Place: Power and Negotiation in the Hair Salon, Gender and Society, 10 (5): 505-526

Gimlin, D. (2007) What is Body Work? A Review of the Literature, Sociology Compass: 1 (1): $353-370$

Hancock, P. and Tyler, M. (2007) Un/doing Gender and the Aesthetics of Organizational Performance, Gender, Work \& Organization 14 (6): 512-533.

Kang, M. (2003) The Managed Hand: The Commercialisation of Bodies and Emotions in Korean Immigrant Owned Nail Salons, Gender and Society, 17 (6): 820-839

Kvale, S and Brinkman, S (2009) Interviews: Learning the Craft of Qualitative Research Interviewing, London: Sage

Kosut, M (2006) An ironic Fad: The Commodification and Consumption of Tattoos, The Journal of Popular Culture, 39 (6): 1035-1048.

Lane, D (2014) Tat's All Folks: An Analysis of Tattoo Literature, Sociology Compass, 8 (4): $398-410$.

MacAdams, L (2001) Birth of the Cool, New York: Free Press.

McCrindle blog: http://www.mccrindle.com.au/the-mccrindle-

$\underline{\log / \text { tattoos_in_australia_perceptions-_trends_and_regrets, accessed 3.7.17 }}$

Modesti, S (2008) Home Sweet Home: Tattoo Parlors as Postmodern Spaces of Agency, Journal of Communication, 72 (3): 197-212.

Patterson, M and Schroeder, J (2010) Borderlines: Skin, Tattoos and Consumer Culture Theory, Marketing Theory, 10 (3): 253-267. 
Pettinger, L. (2010) Brand Culture and Branded Workers: Service work and Aesthetic Labour, Consumption, Markets and Culture, 7 (2): 165-184

Porteous, D. (1986) Bodyscape: The Body and Landscape Metaphor, The Canadian Geographer, 30 (1): 2-12

Roberts, J (2012) Secret Ink: Tattoo's Place in Contemporary Culture, The Journal of American Culture, 35:2, 153-165.

Timming, A (2014) Visible Tattoos in the Service Sector: A New Challenge to Recruitment and Selection, Work Employment and Society, 29 (1|): 60-78.

Tyler, M. and Cohen, L. (2010) Spaces that Matter: Gender Performativity and Organizational Space. Organization Studies 31 (2): 175-198.

Urbandictionary.com accessed 15.7.16

Warhurst, C. and Nickson, D. (2007a) Employee Experience of Aesthetic Labour in Retail and Hospitality, Work Employment and Society, 2 (1): 103-120

Warhurst, C. and Nickson, D. (2007b) A New Labour Aristocracy? Aesthetic Labour and Routine Interactive Service Work, Work Employment and Society, 2 (4): 785-798

Warren, S (2008) Empirical Challenges in Organizational Aesthetics Research: Towards a Sensual Methodology. Organization Studies, 29(4), 559-580.

Warren, C and Campbell, M (2014) What Makes Things Cool? How Autonomy influences perceived coolness, Journal of Consumer Research, 41, August 543-563.

Wicks, D and Grandy, G (2007) What Cultures exist in the Tattooing Collectivity? Ambiguity, Membership and Participation, Culture and Organization, 13 (4): 349-363. 
Witz, A., Warhurst, C. and Nickson, D. (2003) The Labour of Aesthetics and the Aesthetics of Labour, Organization, 10 (1): 33-54

Wolkowitz, C. (2002) The Social Relations of Body Work, Work Employment and Society, 16 (3): $497-510$

Wolkowitz, C. (2006) Bodies at Work, London: Sage

Fig 1: A tattooists sitting at his 'work station'

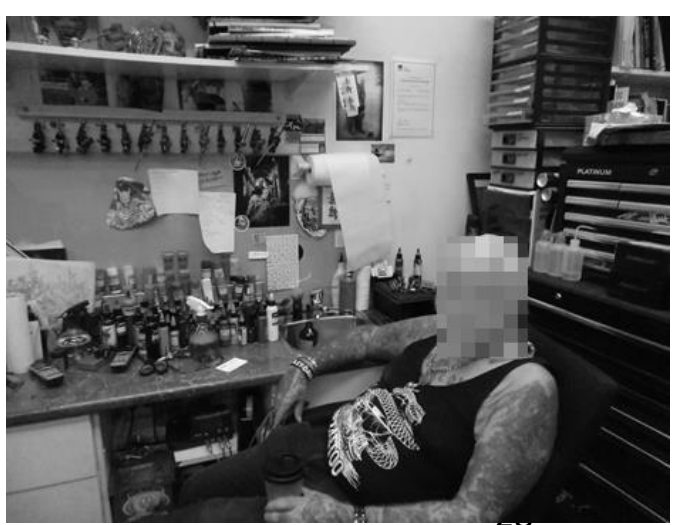


Fig 2: Body markings of four tattooists from the study
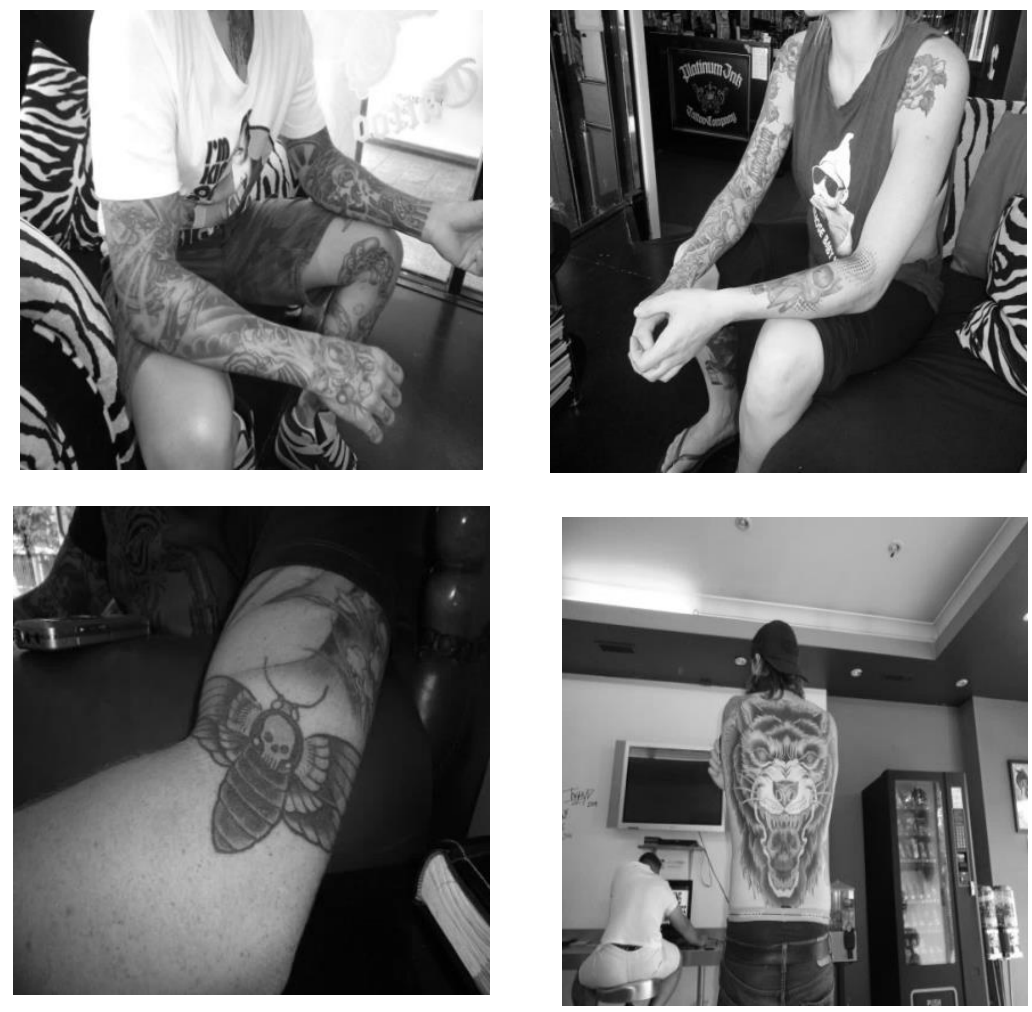